\title{
Finite Element Analysis of Epoxy (Ly-556) Glass Fiber Filled Aluminium Circular Section Hollow Column
}

\author{
Dr.M.AnandaRao ${ }^{1}$, Dr.K.Vijaya Kumar Reddy ${ }^{2}$, T.Seshaiah ${ }^{3}$. \\ ${ }^{1}$ Professor, Department of Mechanical Engineering, MLR institute of Technology, Dundigal, Hyderabad. \\ ${ }^{2}$ Professor, Department of Mechanical Engineering, JNTU College of Engineering, Hyderabad. \\ ${ }^{3}$ Associate Professor, Department of Mechanical Engineering, QIS College of Engineering \& Technology, \\ Ongole,
}

\begin{abstract}
Composite materials are materials made from two or more constituent materials. It consists of a continuous phase called matrix, and a discontinuous phase called reinforcing material. Both matrix and reinforcing materials have significantly different physical or chemical properties, that when combined, produce a material with characteristics different from the individual materials. Fiber composites materials offer a combination of strength and elasticity that are better than conventional metallic materials. The anisotropic nature of a FR composite material creates a unique opportunity of tailoring its properties according to the design requirements.

The idea of filling the particulate polymer composite material in an aluminum tube is taken from a research paper presented at $14^{\text {th }}$ International conference on computing in civil and building engineering in Moscow, Russia (27-29 June 2012) by Feng Zhou and Ben Young, in which they filled the Al tube with concrete and conducted finite elemental analysis. The composites used in the project is epoxy-glass fiber sample is taken in a hollow $\mathrm{Al}$ tube and tested for crushing load. These sample is then modeled by ANSYS.

Unlike conventional materials, the properties of the composite materials can be designed considering the structural aspects. The composites have a key role to play in the fast growing markets like automobiles, marine, applications like propeller vanes, fans, blowers, gear cases and valves. Stiffness of the test specimens largely depend on particle loading, the combination of these composite materials can be used in frames of buses, cars, and in shipbuilding industries, as vertical columns and in many other fields.
\end{abstract}

\section{INTRODUCTION}

Composite materials are materials made from two or more constituent materials with significantly different physical or chemical properties, that when combined, produce a material with characteristics different from the individual components. The individual components remain separate and distinct within the finished structure.

Composite structures, used to meet the demand for lightweight, high strength/stiffness and corrosionresistant materials in domestic appliances, aircraft industries and fields of engineering composites, have been one of the materials used for repairing the existing structures owing to its superior mechanical properties. Applications of composite materials have been extended to various fields, including aerospace structures, automobiles and robot systems.

Composite materials are not homogeneous. Their properties are dependent on many factors, the most important of which are the type of fiber, quantity of fiber (as volume fraction) and the configuration of the reinforcement. They are generally completely elastic up to failure and exhibit neither a yield point nor a region of plasticity. The properties of composites are dependent on the properties of the fiber and the matrix, the proportion of each and the configuration of the fibers. If all the fibers are aligned in one direction then the composite relatively stiff and strong in that direction, but in the transverse direction it has low modulus and low strength.

FR composites materials offer a combination of strength and elasticity that are better than conventional metallic materials. Composites are superior because of their low specific-gravities, strength-weight ratios. Structural materials such as steel and aluminum alloys are considered isotropic since they exhibit nearly equal properties irrespective of the direction of measurement. Composites consist of two or more phases that are usually processed separately and then bonded, resulting in properties that are different from those of either of the component materials. For many years glass composites have had a distinct strength to weight advantage. Although the rapid evolution of carbon and aramid fibers has gained advantages, glass composite products have still prevailed in certain applications. Resin is a generic term used to designate the polymer, polymer precursor material, and/or mixture or formulation thereof with various additives or chemically reactive components. The resin, its chemical composition and physical properties, fundamentally affect the processing, fabrication and 
ultimate properties of composite materials. Fillers are inert substances added to reduce the resin cost and/or improve its physical properties, viz., hardness, stiffness and impact strength.

\section{FABRICATION OF FRP COMPOSITES}

FRP fabrication consists of suitably combining reinforcement material (glass fiber or carbon fiber) with a matrix material (resin) by a suitable production, process and of curing the resulting moulding into the required product. Fabrication Techniques of composites are (i) making the product by moulding it into shape(ii) making the product by winding the filaments(iii)Making the product by continuous on line production methods(iv)Making the product by centrifugal casting. Hand Lay-up Process is used for the fabrication of the test pieces.

\subsection{PROCEDURE OF MAKING THE TEST PIECES:}

The resins and the glass fibers are taken in the ratio $80: 20$ by weight and mixed thoroughly by using a brush until both the resin and the glass fibers form a pasty mixture. Then this mixture is poured in a hollow aluminum tube closed at one end carefully without disturbing the aluminum tube. It is then left to dry for about 24 to 48 hours.

\section{Test Piece 1 (GP resin with Glass Fibers in Al hollow tube)}

In a mixing jar or pot, we have taken $900 \mathrm{gms}$ of GP resin with accelerator (cobalt) as $15 \%$ and catalyst (methanol) as $15 \%$. The mixture should be mixed thoroughly with a long stick and a mask should be wore because GP resin is very harmful to health if it is inhaled. It should be mixed completely so that the resin is uniform in every part of mixture. Before to that the glass fibers have to cut as small pieces with equal dimensions. The type of glass fiber used is E-glass. We have four types of glass fiber clothes i.e, Glass, Roving, CSM and UD (unidirectional). The glass type we have taken is vowen roving of $400 \mathrm{grade}$ and it is $120 \mathrm{gms}$ in weight. The glass fiber is mixed with the resin and this mixed one is put in the Al hollow tube. The air gaps and voids are avoided by pressing the mixture of glass fiber and resin uniformly into the tube by the rod of same diameter as $\mathrm{Al}$ tube. It will take nearly a whole day for this test piece to dry as we have used GP resin. GP resin will take nearly $24 \mathrm{hr}$ to dry. Next day when the test piece is fully dried, we have to keep it for curing for 7-8 days at room temperature. By seeing the IS standard book, we have marked the dimensions for crushing strength testing.

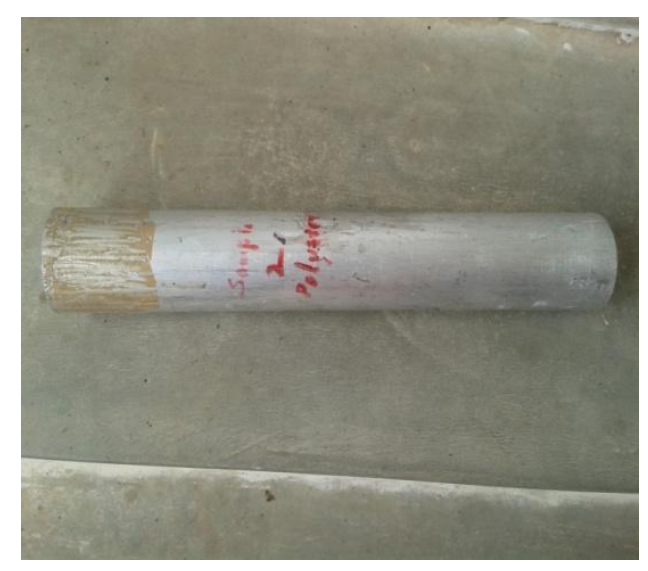

Fig: 2.1.1 Glass fibers with polyester resin in Aluminum tube

\section{Test Piece 2 (Epoxy resin with glass fiber in Al hollow tube)}

In a mixing jar or pot, we have taken $900 \mathrm{gms}$ of Epoxy resin with diluter 072 as $10 \%$ and Ordinary resin 758 as $10 \%$. The mixture should be mixed thoroughly with a long stick and a mask should be wear because Epoxy resin is very harmful to health if it is inhaled. It should be mixed completely so that the resin is uniform in every part of mixture. Before to that the glass fibers have to cut as small pieces with equal dimensions. The type of glass fiber used is E-glass. The glass type we have taken is vowen roving of 400 grade and it is $120 \mathrm{gms}$ in weight. The glass fiber is mixed with the resin and this mixed one is put in the Al hollow tube. The air gaps and voids are avoided by pressing the mixture of glass fiber and resin uniformly into the tube by the rod of same diameter as $\mathrm{Al}$ tube. It will take nearly a whole day for this test piece to dry as we have used Epoxy resin. Epoxy resin will take nearly 24-48hrs to dry. Next day when the test piece is fully dried, we have to keep it for curing for 7-8 days at room temperature. By seeing the IS standard book, we have marked the dimensions for crushing strength testing. 


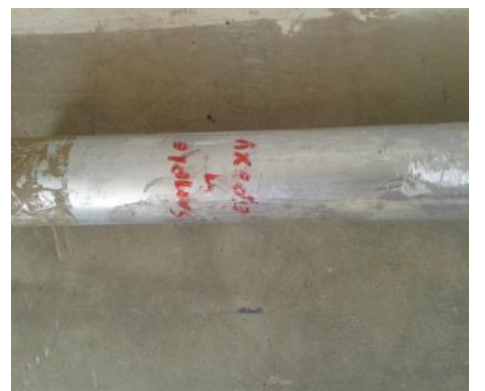

Fig: 2.1.2 Glass fibers with Epoxy resin in Al tube

\section{Test Piece 3 (Epoxy with glass fiber without Al hollow tube)}

In a mixing jar or pot, we have taken $900 \mathrm{gms}$ of Epoxy resin with diluter 072 as $10 \%$ and Ordinary resin 758 as $10 \%$. The mixture should be mixed thoroughly with a long stick and a mask should be wore because Epoxy resin is very harmful to health if it is inhaled. It should be mixed completely so that the resin is uniform in every part of mixture. Before to that the glass fiber has to cut as small pieces with equal dimensions. The type of glass fiber used is E-glass. The glass type we have taken is vowen roving of 400 grade and it is $120 \mathrm{gms}$ in weight. The glass fiber is mixed with the resin and this mixed one is put in the PVC hollow pipe. The air gaps and voids are avoided by pressing the mixture of glass fiber and resin uniformly into the tube by the rod of same diameter as PVC pipe. It will take nearly a whole day for this test piece to dry as we have used Epoxy resin. Epoxy resin will take nearly $24-48 \mathrm{hrs}$ to dry. Next day when the test piece is fully dried, we have to keep it for curing for 7-8 days at room temperature. After curing we cut that PVC pipe. By seeing the IS standard book, we have marked the dimensions for crushing strength testing

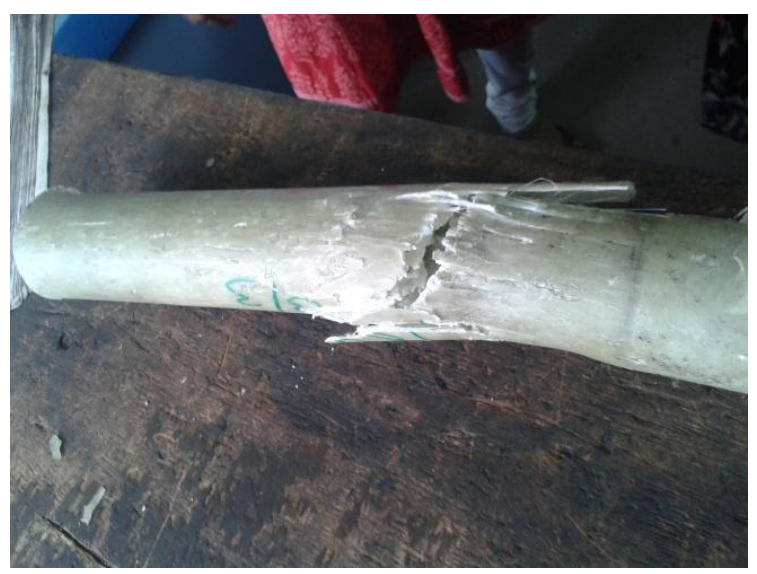

Fig: 2.1.3 Epoxy with glass fibers

\section{FINITE ELEMENTAL ANALYSIS OF FIBER COMPOSITE COLUMNS IN HOLLOW AL TUBE}

3.1 STATIC ANALYSIS:

The performance of a material is judged by its properties and behavior under compressive, tensile and bending constraints these properties are also known as static mechanical properties of the materials. In our project we are subjecting cylindrical composite test specimens to compressive loads because all structural columns are primarily subjected to compressive loads.

\section{Compression testing of Composites filled in hollow Al column:}

In addition to tensile and flexural testing, another common form of determining the material properties of fiber (both no reinforced and reinforced) is compression testing. This test is useful for determining the modulus of elasticity, yield stress, compressive strength, and deformation beyond yield point. The method by which the compression test is conducted is defined in ASTM D695. 


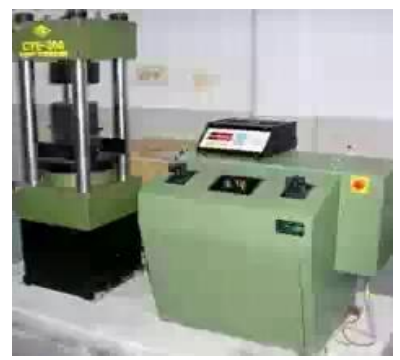

Fig: 3.1 UTM used for compression testing of columns

Table: 3.1 Dimensions of the specimens made are given in the tabular column below:

\begin{tabular}{|c|c|c|c|}
\hline S.NO. AND SPECIMEN & $\begin{array}{c}\text { DIAMETER OF } \\
\text { COLUMNS(mm) }\end{array}$ & $\begin{array}{c}\text { LENGTH OF } \\
\text { COLUMNS(mm) }\end{array}$ & $\begin{array}{c}\text { LENGTH TO } \\
\text { DIAMETER RATIO }\end{array}$ \\
\hline $\begin{array}{c}\text { 1.Epoxy and glass fiber in } \\
\text { hollow Al column }\end{array}$ & 50.35 & 310 & 6.15 \\
\hline $\begin{array}{c}\text { 2.Epoxy and glass fiber } \\
\text { without Al column }\end{array}$ & 47.33 & 310 & 6.5 \\
\hline $\begin{array}{c}\text { 3.Polyster and glass fiber } \\
\text { filled in hollow Al column }\end{array}$ & 50.40 & 310 & 6.15 \\
\hline
\end{tabular}

We tested all the specimens at Jyothi Spectra Analysis an NABL certified laboratory at balanagar Hyderabad. After compression test on all the specimens the results were tabulated in the tabular column below.

Table: 3.2 Compressive test results:

\begin{tabular}{|c|c|c|c|}
\hline S.No & Specimen & $\begin{array}{c}\text { Ultimate } \\
\text { Compressive } \\
\text { load(KN) }\end{array}$ & $\begin{array}{c}\text { Compressive } \\
\text { stress(Mpa) }\end{array}$ \\
\hline 1 & $\begin{array}{c}\text { Al ( Epoxy } \\
\text { glass fiber) }\end{array}$ & 203.9 & 120.64 \\
\hline 2 & $\begin{array}{c}\text { Epoxy+ glass } \\
\text { fiber }\end{array}$ & 62 & 35.2394 \\
\hline 3 & $\begin{array}{c}\text { Al(Polyester + } \\
\text { glass fiber ) }\end{array}$ & 176.2 & 88.0045 \\
\hline
\end{tabular}

\subsection{FINITE ELEMENT ANALYSIS:}

Finite Element Analysis is a mathematical representation of a physical system comprising a part/assembly (model), material properties, and applicable boundary conditions \{collectively referred to as (preprocessor), the solution of that mathematical representation (solution processor), and the study of results of that solution (post processor). Simple shapes and simple problems can be, and often are, done by hand. Most real world parts and assemblies are far too complex to do accurately, let alone quickly, without use of a computer and appropriate analysis software.

\section{ANSYS Preprocessor}

Model generation is conducted in this processor, which involves material definition, creation of a solid model, and, finally, meshing. Important tasks within this processor are:

- Specify element type.

- Define real constants (if required by the element type).

- Define material properties,

- Create the model geometry.

- Generate the mesh.

Although the boundary conditions can also be specified in this processor, it is usually done in the Solution Processor,

\section{ANSYS Solution Processor}

This processor is used for obtaining the solution for the finite element model that is generated within the Preprocessor, Important tasks within this processor are:

- Define analysis type and analysis options, 
- Specify boundary conditions.

- Obtain solution.

\section{ANSYS General Postprocessor:}

In this processor, the results at a specific time (if the analysis type is transient) over the entire or a portion of the model are reviewed. This includes the plotting of contours, vector displays, deformed shapes, and listings of the results in tabular format.

Table: 3.3 Ansys results are shown in the following Table for Epoxy-glass fiber composite with Al:

\begin{tabular}{|c|c|c|}
\hline SPECIMEN & $\begin{array}{c}\text { MAX COMPRESSIVE } \\
\text { STRESS } \\
\text { (EXPERIMENTAL) }\end{array}$ & $\begin{array}{c}\text { MAX COMPRESSIVE } \\
\text { STRESS ( ANSYS ) }\end{array}$ \\
\hline $\begin{array}{c}\text { Epoxy + glass } \\
\text { fiber }\end{array}$ & $120.64 \mathrm{Mpa}$ & $124.765 \mathrm{Mpa}$ \\
\hline
\end{tabular}

Fig: 3.4 Epoxy-Glass Fiber in Al (Ansys):
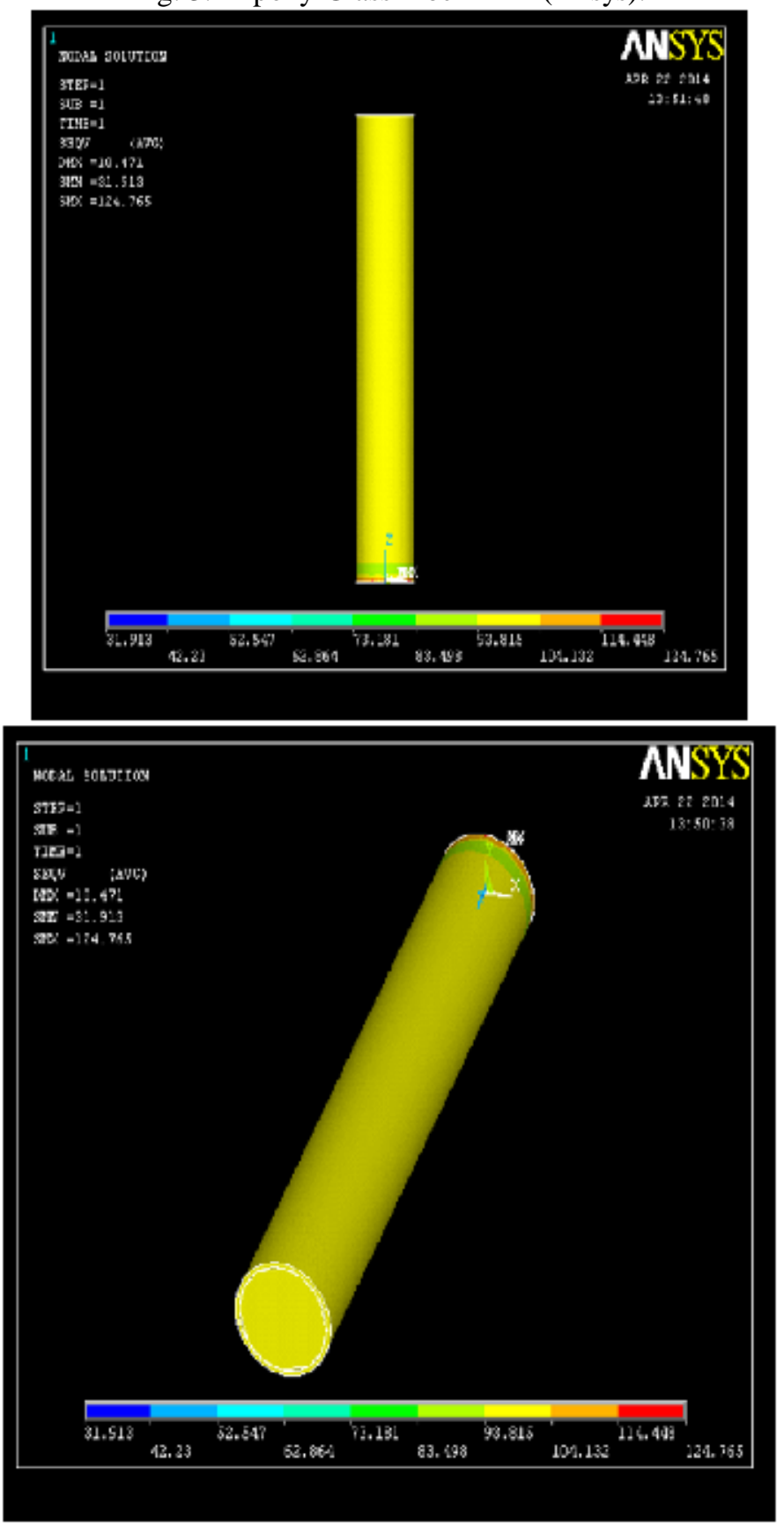
IV. CONCLUSIONS

\begin{tabular}{|c|c|}
\hline SPECIMEN & $\begin{array}{c}\text { MAX COMPRESSIVE } \\
\text { STRESS (MPa) }\end{array}$ \\
\hline $\mathrm{Al}$ ( Epoxy + glass fiber) & 120.64 \\
\hline Epoxy + glass fiber & 35.2394 \\
\hline $\mathrm{Al}$ ( Polyester + glass fiber ) & 88.0045 \\
\hline
\end{tabular}

In our project we obtained better compressive strengths for the composites filled in $\mathrm{Al}$ column as shown in the table. Both (Epoxy + Glass fiber) and (Polyester + glass fiber) with Al tube failed at $120.64 \mathrm{MPa}$ and 88.0045 MPa respectively. But however, Epoxy - glass fiber without Al tube gave low strength values 35.2394 Mpa.

These columns can be used in the following applications

Composite-Filled Al tubes (CFTs) are composite members consisting of an hollow Al tube in filled with composite material. CFT columns can be used in the primary lateral resistance systems of both braced and no braced building structures. There exist applications CFT's as bridge piers. Moreover, CFTs may be utilized for retrofitting purposes for strengthening earthquake zones.

\section{REFERENCES}

[1] Mikata, Y and Jaya, M.,' Stress field in a coated continuous FC subjected to thermal loads", J.composite materials, Vol.19, p.554, 1985.

[2] Gradin, P.A.,"Inter-laminar fracture of composite materials",J.composite materials, Vol.15, p.386, 1982.

[3] Chen,J.K.,Sun,C.T.,and Chang,C.I.,"'Failure analysis of a graphite laminate subjected to combined thermal and mechanical loading",J.composite materials, Vol.19,p.408,1985.

[4] Ketan,R.P.andChang,D.C.,"Surface damage in composites due to impact load"J.composite materials, Vol.17,p.182,1983.

[5] Joshi, S.P.and Sun, C.T.,"impact induced fracture of composites",J.composite materials, Vol.19, p.51, 1985.

[6] Young, H., Wu, T.and Springer, G.S.,'Impact induced stresses, strains and delamination in composite plates",J.composite materials, Vol.22, p.533, 1988.

[7] Adams, D.F., and Adams, L.G.,"Tensile impact tests of unidirectional composites in epoxy matrix",J.composite materials, Vol.24, p.256, 1990.

[8] L.L. Lorenzu and H.T. Hahn, 'Fatigue and Fracture', ASTM STP 907, 210 (1986).

[9] H.T. Hahn and R.Y. Kim, J. Composite Mater., 10, 156, (1976).

[10] B.D. Agarwal and J.W. Dally, J. Mater. Sci., 10. 196, (1975).

[11] Plastic Institute (London), p.292 (1971). 